Págs. 14-29

\title{
Francia: jinstrumentalización de la COVID-19 contra la igualdad escolar?
}

\section{France: Instrumentalization of the COVID-19 Against School Equality?}

\author{
Stéphane Bonnéry'
}

\section{Resumen}

La pandemia de COVID-19 ha puesto a prueba los sistemas educativos. Este artículo trata del caso francés, en el que tuvo lugar un confinamiento de dos meses, seguido de una reanudación muy parcial y selectiva del curso antes del verano, que no llegó a funcionar de nuevo realmente hasta septiembre, en condiciones sin precedentes. Muestra que lejos de ser un paréntesis excepcional, la crisis sanitaria fue utilizada por el gobierno para tratar de imponer cambios estructurales. Estas conclusiones se derivan de un análisis de las lógicas que estaban previamente en marcha en los proyectos de reforma de la enseñanza francesa, lo que permite distinguir entre las respuestas puntuales a una situación excepcional de los intentos de instrumentalizar la pandemia. De este modo, las tentativas del Gobierno suponen una renuncia a la igualdad y a la democratización escolar, pues reducen los contenidos que se enseñan a todo el alumnado y derivan a las familias la responsabilidad y la financiación de disciplinas enteras y de contenidos de otras asignaturas, mediante el desarrollo de la educación a distancia y la transferencia al sector privado y a las autoridades locales de contenidos que finalmente no se incluirían en los planes de estudios nacionales. Estas políticas de repliegue público y de competencia entre el alumnado se derivan de lógicas que ya están en funcionamiento, dado que el sistema educativo francés ha sido objeto hasta ahora de un compromiso inestable entre lógicas de selección social y lógicas de democratización de los estudios.

\section{Palabras clave}

COVID-19, Francia, política educativa, desigualdades escolares, reformas escolares.

\section{Abstract}

The COVID-19 pandemic has put education systems to the test. This article deals with the French case, whose educational system was confined for two months, then resumed very partially and selectively before the summer, only really functioning again in September, under unprecedented conditions. It shows that far from being an exceptional parenthesis, the health crisis was used by the government to try to impose structural changes. These conclusions stem from an analysis of the rationale that was previously under way in the projects to reform French education, which makes it possible to distinguish between punctual responses to an exceptional situation and attempts to exploit the pandemic. The government's attempts to renounce to equality and school democratisation, by reducing the content taught to all pupils, to transfer to families the responsibility and financing of entire disciplines and the content in other subjects, through the development of online learning, and the transfer to the private sector and local authorities of some educational content that would no longer be included in national curricula in the long term. These policies of public disengagement and competition among pupils are the result of approaches which are already at work, since the French education system has hitherto been the subject of an unstable compromise between the logic of social selection and the logic of democratisation of studies.

\section{Keywords}

COVID-19, France, educational policy, school inequalities, school reforms.

\section{Cómo citar/Citation}

Bonnéry, Stéphane (2021). Francia: ¿instrumentalización de la COVID-19 contra la igualdad escolar?. Revista de Sociología de la EducaciónRASE, 14 (1), 14-29. http://dx.doi.org/10.7203/RASE.13.4.18223.

\footnotetext{
1 Departamento de Ciencias de la Educación, Universidad París 8, grupo de investigación CIRCEFT-ESCOL. Contacto: stephane.bonnery@univ-paris8.fr. Texto traducido por Rafael Feito y revisado por Javier Rujas.
} 


\section{Introducción}

En todos los países afectados por la pandemia del coronavirus, los sistemas escolares se han visto trastornados, en particular, como ha sido el caso en Francia, cuando se ha puesto en marcha un sistema de confinamiento, lo que ha provocado una situación inédita en 2020. De hecho, Emmanuel Macron, el presidente de la República, anunció el 12 de marzo la decisión de cerrar todas las escuelas y universidades a partir del 17 de marzo hasta nuevo aviso. El ministro de Educación, Jean-Michel Blanquer, exigió que los profesores, los alumnos y los padres montaran la «escuela en casa» para asegurar la «continuidad pedagógica», instando a la enseñanza «a distancia». En abril, mayo y junio, nuevas directrices e instrucciones a veces contradictorias, con apenas unos días de diferencia, hicieron que se reanudasen las clases en los centros de primaria y de secundaria de primer ciclo (collège), primero para una parte del alumnado, y luego en modalidades diversas para otros niveles (mayoritariamente a tiempo parcial) ${ }^{2}$. Mientras, el examen final de bachillerato se había suspendido y transformado en un sistema de evaluación continua, y los estudiantes de secundaria segunda etapa y de universidad no volverían a sus centros antes del verano ${ }^{3}$. Cuando se escriben estas líneas, a principios de septiembre de 2020, el inicio del curso escolar se está produciendo en condiciones relativamente poco claras, con unas condiciones de seguridad muy precarias y con la ocultación oficial de información sobre el número de escuelas cerradas debido a la COVID.

Pero ¿se deben realmente los profundos y brutales cambios que está experimentando el sistema escolar francés sólo a una respuesta «técnica» a la pandemia? Este artículo pretende mostrar que, en varios aspectos, no es así y que la pandemia se está instrumentalizando para imponer «reformas» ya previstas, pero que las circunstancias conducen a acelerar, para renunciar a la igualdad de objetivos entre alumnos de diferentes clases sociales.

Demuestra, además, que las lógicas que subyacen a los cambios en curso no «crean» las desigualdades, que ya existían, sino que estas lógicas rompen el compromiso entre justicia social y selección social que ha prevalecido en educación desde finales de los años cincuenta.

Antes de pasar al análisis de la «crisis COVID», detallaremos los métodos de investigación en los que se basa este artículo, luego se hablará sobre la situación del sistema escolar francés y la «crisis» que le afecta desde hace varios decenios y que explica las consecuencias educativas de la pandemia, así como su posible utilización por las autoridades.

\section{Analizar los cambios en curso con herramientas de investigación}

En los seis meses transcurridos entre el inicio del confinamiento y el comienzo del curso en septiembre, se han difundido multitud de comentarios públicos sobre la actualidad. Algunos de ellos, enmarcados por

2 En el sistema educativo francés, la educación era hasta ahora obligatoria de los 6 a los 16 años, como en España, pero desde el comienzo del curso $2020-2021$ la educación obligatoria comienza a los 3 años y los jóvenes de entre 16 y 18 años tienen «obligación de formación»en sentido amplio (deben formarse a través de un empleo, del servicio cívico, de distintos programas de acompañamiento e inserción profesional, de prácticas profesionales o a través de la enseñanza formal). En Francia, la educación primaria (CINE1) dura cinco cursos (de los 6 a los 10 años) y la primera etapa de secundaria (el collège, CINE2) dura cuatro (de los 11 a los 15), que se cierra con un examen nacional (el Diplôme National du Brevet). A continuación, los itinerarios postobligatorios (CINE3) se dividen entre el bachillerato general, el tecnológico y el profesional (este último equivalente de nuestra FP), todos ellos de tres años. También se puede cursar una formación profesional de dos años, que da lugar a un certificado de aptitud profesional (CAP) o a un diploma de estudios profesional (BEP). A la universidad se accede por lo general tras superar el examen final de bachillerato (baccalauréat). (Nota del revisor).

3 Este artículo se centra en la educación primaria y secundaria. La situación de la enseñanza superior merecería un análisis específico: las universidades también se cerraron sin que volvieran a abrir antes del verano, y a principios de septiembre, unos días antes de que comiencen las clases, muchos profesores de enseñanza superior no saben si impartirán clases presenciales, a distancia o en formatos híbridos. Inmediatamente después del confinamiento, algunos universitarios recurrieron a diversos métodos de investigación para identificar las consecuencias del confinamiento sobre sus estudiantes y las razones por las que pueden o no seguir ocupándose de sus estudios. Para una visión general de estos trabajos, véase: Millet y Vaquero, 2020; Henri-Panabière, Mercklé y Gouasdé, 2020. Estos capítulos se inscriben en una obra que, de manera más general, analiza los efectos sociales del confinamiento en todos los niveles de la escolaridad en términos de política educativa y de pedagogía (Bonnéry y Douat, eds., 2020). 
el poder de los medios de comunicación dominantes, se limitaban a un horizonte de preguntas presentadas como puramente técnicas por el gobierno, a pesar de que se trataba de opciones políticas: «¿Los profesores están mandando demasiados deberes durante el confinamiento o no los suficientes?» (mientras que se sucedían los mandatos contradictorios por el poder público y en la mayoría de los casos no se proporcionaba ningún material informático a los profesores); «¿A favor o en contra de la reanudación de las clases el 11 de mayo?» (negándose a mencionar las condiciones a medio plazo, lo que llevó a que no se presentara ninguna garantía de escolarización segura para septiembre); «¿A quién debe darse prioridad para beneficiarse de la reescolarización?» (con el fin de poner a las familias en competencia entre sí una vez se produjera la reanudación parcial de la escolaridad en junio); etc. Otros comentarios, especialmente en la prensa de izquierdas e independiente de los principales grupos financieros, fueron esencialmente críticos con la «improvisación» ministerial o, más bien, con las manipulaciones intencionadas.

Para protegerse de estos enfoques periodísticos o meramente militantes limitados a visiones inmediatas, este artículo recurre a las herramientas teóricas de la investigación educativa: historia y sociología de las políticas educativas, estudio socio-didáctico de los programas escolares y de los procesos de enseñanza-aprendizaje. Así pues, pretende reflexionar con distancia sobre las transformaciones en curso y, para ello, identificar las lógicas ya en funcionamiento en la escuela que se han exacerbado o han conocido transformaciones con la crisis de la COVID. Entre estas diferentes lógicas, nos centraremos en aquellas cuyos cambios parecen tener consecuencias duraderas en las políticas escolares, y en particular en la "escolaridad única”, es decir, en el caso francés, las escuelas públicas (laicas y gratuitas) que persiguen los mismos objetivos para todos los alumnos, de todas las clases sociales, integrando la educación infantil (de 2 a 6 años), la primaria (de 6 a 11 años) y el primer ciclo de secundaria (de 11 a 14 años).

Este trabajo se basa en datos recogidos a distancia debido al confinamiento. Aunque parciales, en su recopilación se ha tratado de cotejar distintos puntos de vista y diferenciar las características sociales de los encuestados. Se recogieron testimonios por teléfono o a través de mensajes digitales (a veces escritos, a veces en respuestas cortas a preguntas específicas) de profesores de los diferentes niveles de la escolaridad única (14 profesores titulares de diferentes edades y 5 aprendices que supervisamos en el programa de maestría del MEEF) ${ }^{4}$, así como de progenitores (23, en su mayoría madres). Se contactó con ellos a través de conocidos que participaron en investigaciones anteriores o en cuatro grupos de redes sociales de los que somos miembros (localizando los mensajes sobre este tema y contactando individualmente a los miembros) ${ }^{5}$. También hemos incluido testimonios de algunos de estos participantes sobre vecinos o padres que apenas tenían posibilidades de conexión con el fin de reducir el sesgo de investigar únicamente a los más familiarizados con los intercambios escritos a distancia. Todo ello se complementa con los resultados de las investigaciones realizadas durante el mismo periodo que hemos coordinado o pedido a otros.

4 Métiers de l'enseignement, de l'éducation et de la formation (Profesiones de la enseñanza, la educación y la formación). En Francia, acceden a esta formación estudiantes de diferentes disciplinas después de un grado universitario (3 años) y se forman durante dos años para que convertirse en maestros de escuela (como los estudiantes de nuestra muestra) o en profesores de instituto. Esta formación combina exámenes para obtener un máster ( 2 años), prácticas y oposiciones para los cuerpos docentes.

5 Un grupo creado por una asociación de padres (poco politizada, principalmente madres, de todos los orígenes, pero con predominio de las clases medias); una lista de discusión creada para las elecciones municipales de marzo de 2020 (a favor de una lista sindical de izquierda, cuyos miembros pertenecen a diversas categorías sociales) que se convirtió en un foro sobre la actualidad durante el confinamiento; un grupo de padres y organizadores de un club de rugby (cuyos miembros proceden de categorías sociales muy diversas y votan a distintas fuerzas, aunque con bastante frecuencia de derechas); y otro formado por amigos que residen en regiones muy diversas, a menudo con títulos educativos relativamente altos, profesores o padres de alumnos. 


\subsection{5 años de políticas divididas entre la democratización y la selección}

Si bien la crisis de la COVID acelera las desigualdades educativas, no las crea. Recordemos rápidamente la situación del sistema escolar francés, que es el resultado de un compromiso inestable que se ha construido históricamente.

La historia de la escolarización en la mayoría de los países occidentales, y en particular en Francia, es el resultado de una lucha entre dos lógicas principales. Por una parte, la democratización del acceso a la educación (primaria, luego secundaria, luego superior) es el resultado de una convergencia recurrente, en diferentes momentos sucesivos, entre varios fenómenos: la aspiración cada vez más extendida entre las clases trabajadoras de que sus hijos tengan acceso a la educación y a los títulos, el deseo de las categorías intermedias de mejorar la escolaridad de sus hijos, la necesidad económica de trabajadores más cualificados en ciertos sectores de la economía, el deseo de ciertas fracciones de la burguesía gobernante de educar o domesticar a las clases trabajadoras. Por otra parte, la lógica de selección social apareció en cada etapa de democratización para limitarla, con el fin de no ofrecer exactamente la misma educación a todas las clases sociales, de obstaculizar la consecución de estudios para todos, de sustituir el aprendizaje en común y en solidaridad por la competencia y la individualización.

De este modo, la creación de una escuela primaria por la burguesía de la Tercera República (en los años 1880) fue un gran paso hacia la democratización (un programa nacional para todos los niños y niñas en esta red escolar que concentraba a las familias que no podían pagar sus estudios), al mismo tiempo que limitaba esta escolarización a una aspiración mucho menor que la de los niños de las clases dominantes. El aumento gradual, pero contenido, durante la Tercera y luego la Cuarta República, del número de becarios que ingresaban a la escuela secundaria se limitaba a las necesidades de los empleadores. Posteriormente, la unificación de la educación primaria y el acceso generalizado al primer ciclo de educación secundaria (collège) dieron lugar a la creación de itinerarios en esta última a finales de los años 50. Posteriormente, la unificación de la escuela media y el acceso masificado a la secundaria superior (bycée) dieron lugar a una selección en función de las modalidades de especialización en este nivel. Esta relación dialéctica entre las lógicas de democratización y de selección se extendió a continuación a la enseñanza superior (Terrail, 1984, 1997; Clot, 1988; Rochex, 1991; Poullaouec y Lemêtre, 2009) ${ }^{6}$.

La oposición entre estas dos lógicas se tradujo en primer lugar, desde los años sesenta hasta principios de los 2000, en avances tendentes a la democratización en lo que respecta al acceso a los niveles de educación y a los itinerarios hasta entonces reservados a las clases dominantes. Tales conquistas se lograron en particular mediante la alianza, dentro de la población asalariada, entre los sectores más populares y los más intelectualizados, alianza que duró hasta los años ochenta. Aunque no todas las categorías sociales se beneficiaron por igual de la extensión de la educación, todas lo hicieron, incluidos los niños de las clases dominantes, que también tuvieron que ir más allá para mantener las posiciones dominantes y asegurar la reproducción social (Bourdieu y Passeron, 1970).

Pero esta relativa democratización del acceso sólo se ha traducido parcialmente en una democratización de la apropiación del conocimiento enseñado. La retórica del «fracaso escolar» a menudo hace que los estudiantes, las familias o los maestros se sientan culpables y es una invitación a renunciar a las políticas democratizadoras (Ben Ayed, 2010). Las desigualdades sociales de apropiación han persistido, y las brechas incluso se ampliaron a principios de la década de los 2000 si consideramos que los estudiantes

6 Todo este párrafo y el anterior se basan en estas referencias. 
que hoy en día obtienen los peores resultados en las pruebas de aprendizaje consiguen una puntuación inferior a la de sus homólogos diez años antes, mientras que los «mejores» estudiantes actuales obtienen mejores resultados que los «mejores» de la década anterior (Bautier, 2011).

De este modo, la escolaridad única es un síntoma de la «crisis» de la escuela, entendida en el sentido de un bloqueo relativo debido a lógicas contradictorias. Formulamos la hipótesis de que la pandemia nos está empujando a salir de un equilibrio precario, para girar a la derecha hacia la renuncia a la igualdad en la política ministerial, o para avanzar hacia una nueva etapa de democratización escolar. Así pues, es en el sentido de la exacerbación de los antagonismos sociales en educación como interpretamos diferentes lógicas que resultan particularmente activas durante el confinamiento y tras su finalización.

\section{Detrás de la enseñanza a distancia, la transferencia a las familias... y al sector privado} Hay que distinguir entre las soluciones a corto plazo, en el contexto excepcional del confinamiento, que son improvisadas, por una parte, y, por otra, aquellas más antiguas que, con la pandemia, se han instalado de forma duradera sin resultar de un proceso democrático de toma de decisiones y que persiguen objetivos distintos de la respuesta a un problema concreto. Las instrucciones del ministro Blanquer sobre el uso de las nuevas tecnologías son, a este respecto, reveladoras de la aceleración en la enseñanza primaria y secundaria de lógicas ya en marcha, y muy avanzadas en el caso de la enseñanza superior.

Durante el periodo de confinamiento, había un riesgo real de desenganche. El recurso a la educación a distancia se hizo necesario. Pero su aplicación revela que el modelo de alumno que preside tácitamente la acción ministerial es el de un niño que dispone de una habitación individual en la que aislarse para estudiar, cuya familia tiene al menos un ordenador equipado con ofimática (y no sólo para actividades de ocio) con una impresora y conexión de banda ancha (para ver las clases por videoconferencia), o incluso varios ordenadores cuando se da el caso de que los padres y los hermanos están teletrabajando simultáneamente. Pronto las exhortaciones ministeriales se toparon con la realidad económica y social: muchos niños tuvieron que hacer sus deberes e incluso estudiar nuevas lecciones sin la posibilidad de aislarse de las actividades de los demás habitantes de la vivienda (incluidas las clases por videoconferencia del hermano mayor), y muchas familias no podían acceder al material didáctico por falta de una impresora y de cartuchos de tinta, que resultan caros cuando hay mucho que imprimir. Del mismo modo, la posesión de un solo teléfono inteligente dificultaba la cumplimentación de fichas o su lectura detallada cuando la herramienta debía ser compartida en el seno de la familia. Este periodo también ha demostrado que la brecha digital en el dominio de las herramientas informáticas no se ha reducido. Sin embargo, como explica Dominique Pasquier, el uso popular de Internet no es el mismo que el de las familias con un alto nivel educativo (Pasquier, 2018). Saber comprar en línea, consultar tutoriales o buscar información no significa automáticamente estar acostumbrado al aprendizaje en línea y a la ofimática (descargar y archivar documentos, escribir un mensaje en la forma adecuada de escribir cartas, archivar un fichero de gran peso con las fotos de las tareas realizadas por el alumno y unirlas en un solo fichero...). Por ejemplo, un padre que es trabajador mecánico da testimonio de las horas dedicadas a resolver estos problemas técnicos: «Pensé que los PDF estaban hechos para que no escribiéramos en ellos, y el profesor de tecnología nos dice que pongamos el pie de foto a las imágenes en un PDF...». Al contrario, una pareja de profesores explica que el confinamiento fue una oportunidad para iniciar a su hijo, un estudiante de secundaria, en estos usos del ordenador: «escanear, enseñar a alguien a escribir formalmente con fórmulas de cortesía, a nombrar y almacenar documentos también, ¡necesitaba aprender a organizarse!». 
Pero para estudiar durante el confinamiento, si bien estas condiciones económicas y técnicas, así como el dominio de la herramienta informática, eran necesarias, no eran suficientes.

En primer lugar, muchos estudiantes de secundaria tuvieron que organizarse por su cuenta. Este modelo de enseñanza a distancia plantea que cada uno es autoemprendedor de su propio aprendizaje, pese a que la autonomía frente al trabajo intelectual es el resultado de un largo proceso de socialización infantil por parte de adultos familiarizados con la cultura de la palabra escrita. En segundo lugar, incluso los alumnos de diferentes edades que se han beneficiado de la supervisión de sus padres se han encontrado con un obstáculo importante, ya presente en las clases anteriormente, especialmente cuando se trata de niños de familias de clase trabajadora, que no están en connivencia con lo que es obvio en la escuela. Los aspectos implícitos de las tareas pedagógicas (Bourdieu y Passeron, 1970) y los malentendidos sociocognitivos (Bautier y Rochex, 1997/2007; Bonnéry, 2007) se presentan incluso en relación con las tareas cuyos objetivos se enuncian: el alumno «trabaja» entonces en un horizonte estrecho, realiza ejercicios fragmentados, tratando de encontrar astucias puntuales disociadas de las cuestiones del conocimiento, y se apropia poco de estas últimas. En el hogar, la cuestión fundamental es cómo guiar al estudiante para que la actividad realizada le permita adquirir conocimientos y no sólo realizar ejercicios para lograr un resultado contextualizado.

Sin embargo, los medios pedagógicos de que disponen los enseñantes en el momento del confinamiento no están concebidos para ser utilizados independientemente de la presencia del profesor, sino para ir acompañados de su palabra y de actividades enmarcadas por interacciones. El envío a distancia de lecciones áridas «a la antigua» no permite movilizar saberes enunciados en el contexto específico de los ejercicios. Tampoco los procedimientos inversos, que prescriben actividades para que los saberes en cuestión sean descubiertos e identificados, «construidos», estuvieron acompañados de fichas que guiasen este proceso de ensayo y error deductivo en ausencia de una regulación por parte del docente. Los testimonios familiares mostraron la terrible exacerbación de las desigualdades cuando se transfiere a las familias la misión de hacer comprender, y ya no sólo de afianzar mediante «deberes» lo que se supone que se ha aprendido en clase. Así pues, las familias más intelectualizadas y próximas al ámbito educativo se han apropiado los procedimientos pedagógicos que subyacen a las tareas (no sin dificultad y dedicándoles mucho tiempo). Las familias con un alto nivel educativo, pero alejadas de los enfoques educativos (ingenieros, gerentes técnicos) «rehicieron las lecciones» de manera magistral cuando el teletrabajo les dejaba tiempo para ello. Mientras, la mayoría de los padres, con una educación limitada y con empleos de ejecución ${ }^{7}$, se esforzaban por entender el propósito de las tareas y por enseñar los conocimientos.

Del lado de los profesores, la crisis ha puesto de relieve que la enseñanza no se limita a enviar enlaces web y a repartir documentos, sino que las dificultades de los alumnos son evidentes. Los profesores, contrariamente a lo que el ministro ha denunciado, han intentado en su inmensa mayoría hacer lo que han podido, desarrollando a veces recursos ingeniosos para mantenerse en contacto con las familias. Entre los muchos ejemplos recogidos: grabación de mensajes de audio individualizados a los padres para pedirles su opinión sobre el trabajo del estudiante, elaboración de casos ejemplares enviados con fotos, etc. Aunque no todo fue eficaz, lejos de ello, la dedicación y el ingenio ante la emergencia fueron evidentes.

\footnotetext{
El autor usa la expresión emplois d'exécution, que designa en francés los empleos asalariados, generalmente desempeñados por obreros o empleados, cuya actividad se basa en la ejecución de tareas prescritas por superiores, por tanto, con baja autonomía. (Nota del revisor).
} 
Y los aprendices, en su segundo año de la maestría del MEEF, desplegaron una energía inhabitual para mantenerse en contacto con el mayor número de estudiantes posible, aunque ellos mismos estaban a menudo en condiciones precarias.

Si bien las desigualdades sociales en materia de aprendizaje se han visto exacerbadas por la enseñanza a distancia durante las circunstancias excepcionales del confinamiento, hay varios indicios que hacen temer que tal vez no se trate de un epifenómeno coyuntural. En primer lugar, los Ministerios de Educación Nacional y de Educación Superior han estado fomentando desde hace algunos años el desarrollo de nuevas tecnologías, creando un mercado en el que las «start up» de las «Ed tech» $\rangle^{8}$ tienen una situación ventajosa. Y Jean-Michel Blanquer reveló rápidamente su concepción de los profesores y el aprendizaje: bastan, según él, adultos que repartan fichas de información y enlaces web para los alumnos ordinarios, el resto serían para «recuperación». Esta es, en esencia, la lógica de la enseñanza por competencias, en dos niveles. En primer lugar, niega que estas capacidades de razonamiento complejo se enseñen; se supone que provienen del interior del alumno y que son activables, o no, por medio de estímulos, por razones específicas del alumno (Bautier, Bonnéry y Clément, 2017). Para Jean-Michel Blanquer, este modelo espontaneísta se basa en concepciones de las neurociencias, en las que el cerebro se esencializa como causa y no como resultado de una formación a través de la experiencia social, y restituye ideologías del pasado, como las de los «dones»o «el niño en el centro», que atribuyen al alumno la responsabilidad individual de su fracaso (Sève, 1964; Rayou, 2000). En segundo lugar, Jean-Michel Blanquer, con la idea de la enseñanza por competencias, promueve una concepción de la neurociencia de inspiración conductista en la que al alumno considerado mediocre (que en realidad no tiene los requisitos previos porque a menudo procede de las clases populares) se le asignan tareas con un horizonte limitado, con vistas a un «retorno a lo básico», «back to basics» (Bautier, Bonnéry, Clément, 2017). Este ministro, siguiendo el ejemplo de gobiernos anteriores, de las nuevas derechas anglosajonas y de PISA, entiende este retorno como un énfasis en las matemáticas y en la lengua, y más precisamente en aspectos fragmentados de estas disciplinas que no pueden ser ignorados, introduciendo una división en el programa escolar francés entre lo que debe enseñarse a todos y lo que debe reservarse para unos pocos. Esta es la lógica central que subyace a la definición de la «base común de conocimientos y habilidades». La promoción de «Ed Tech» como solución duradera en la enseñanza primaria y secundaria (mientras que hasta ahora sólo concernía a la enseñanza superior) mediante una propuesta de ley posterior al confinamiento ${ }^{9}$ se inscribe claramente en esta lógica: más allá de los «fundamentos», los contenidos de conocimiento más ambiciosos pueden deslizarse progresivamente hacia el terreno de lo optativo, de lo que puede estudiarse a distancia, o incluso comercializarse.

La hipótesis de esta lógica subyacente es avalada por el hecho de que es exactamente lo que Jean-Michel Blanquer hizo con la reforma del liceo, rediseñando las modalidades para reducir los costos de la enseñanza, limitando lo que se enseña en cada liceo, sobre todo en la mayoría de los que no tienen una composición social burguesa, y derivando a los jóvenes y a las familias la responsabilidad de acudir al CNED (Centre National d'Enseignement à Distance, Centro Nacional de Enseñanza a Distancia) o a otros dispensarios para acceder a «opciones» cada vez menos ofertadas de forma presencial en el marco del servicio público. La crisis del coronavirus brindó la oportunidad de llevar a cabo un experimento a gran

8 Con este anglicismo contraído, cuyo uso se ha extendido desde 2010, se denominan las «Nuevas Tecnologías de la Educación» que supuestamente facilitan la educación a distancia.

9 Proyecto de ley para introducir la educación digital a distancia en las escuelas secundarias y primarias, registrado en la presidencia de la Asamblea Nacional el 19 de mayo de 2020 con el número 2967. 
escala para extender esta lógica a los niveles primario y secundario, tras haber sido desplegada durante veinte años en la educación superior. ${ }^{10}$

\section{Nuevo public management, retórica marcial e instrumentalización de la crisis}

Esto no quiere decir que todo lo que se acaba de describir sea resultado de un cálculo completamente racional y deliberado desde el comienzo de la crisis. Sencillamente, la intención era la de siempre en la tecnocracia y en las esferas políticas neoliberales: reducir la escuela pública a estos elementos «básicos», tanto para disminuir el gasto público como para mercantilizar el conocimiento, y renunciar a la igualdad en la educación, desarrollando una educación a la carta, oficialmente acorde con individuos, en realidad según los orígenes sociales de los alumnos. Con la crisis sanitaria de la COVID, el gobierno ha instrumentalizado así la situación, que también percibe como una cuestión de necesidad para él. Porque sólo hay dos grandes posibilidades para el año 2020/2021, y después, debido a la creciente crisis económica: o bien reforzar los servicios públicos y, para ello, reorientar el dinero que hasta ahora ha servido principalmente para salvar al sector financiero; o bien mantener el apoyo a este y reforzar las políticas de austeridad. Por lo tanto, las «elecciones» del gobierno no son solo ideológicas, sino impulsadas por la crisis, que las hace más visibles y dicotómicas.

Estos elementos explican la gestión de la vuelta a la escuela. En efecto, cuando se toman en consideración las declaraciones y decisiones ministeriales, se hace todo lo posible para presentarlas solo como técnicas e impuestas con urgencia por la crisis sanitaria, dos razones que llevan a impedir cualquier debate. También debemos añadir el uso de metáforas marciales y naturales por parte del presidente de la República cuando decreta la «guerra contra un tsunami».

Al definir el problema como algo de origen natural, el discurso presenta los hechos como impredecibles, pero desde diciembre de 2019 hasta marzo y luego junio de 2020, los gobernantes del mundo han aprendido mucho gradualmente. Sin embargo, mientras que algunos países, aunque fuesen países en desarrollo como Vietnam (que no comunicó ninguna muerte), contaron con un sistema de salud pública y medidas de emergencia para financiar pruebas y mascarillas, otros prefirieron no asustar al mercado de valores, mantener la producción y no cuestionar las políticas de austeridad que golpean a los servicios públicos y que llevan a negarse a financiar pruebas y mascarillas gratuitas.

Con la metáfora natural, el gobierno sigue presentando los acontecimientos como si se enfrentara a un problema que viene de fuera: pero las políticas de austeridad son una de las causas de la crisis. La política de «stock cero» para maximizar los beneficios conduce a una escasez de mascarillas, la de la deslocalización de las empresas en el lugar más barato desarma las posibilidades de fabricar localmente el equipo necesario cuando más necesario resulta, la ausencia de un diagnóstico sistemático de la COVID-19 proviene sobre todo de razones ideológicas contra su financiación por la seguridad social. La política de financiación de la investigación centrada en las oportunidades «rentables» ha impedido que la investigación básica encuentre soluciones más amplias para los virus emergentes (Canard, 2020). Y el debilitamiento de los servicios públicos a

10 Los MOOC, Massive Open Online Course, son cursos filmados disponibles en páginas web cerradas o abiertas. A menudo se evalúan automáticamente, utilizando cuestionarios de opción múltiple: una vez que se paga al profesor por la creación del curso, este puede ser utilizado a bajo costo a largo plazo. 
través de las políticas de austeridad es la causa fundamental de la gran dificultad de la sociedad para hacer frente a la pandemia.

Su constatación fue sorprendente para los exangües hospitales públicos, pero también para la escuela: si bien el ministro insta a la «continuidad pedagógica», cabe señalar que en Francia está aumentando el número de interinos, que sólo pasan un año en el centro escolar, lo que dificulta considerablemente la tarea de organizar un proyecto durante varios años y de trabajar en equipo para llevar a cabo esos cambios a lo largo del tiempo. Además, durante el período de reclusión de urgencia, uno de los obstáculos ha sido el hecho de que en Francia los maestros no reciben equipo informático de su empleador, que es el Estado; esto sólo ocurre en ciertos territorios, y depende de la voluntad y de las desiguales posibilidades de las autoridades locales. El ministro podía instar a los profesores a utilizar la enseñanza a distancia, pero la realidad era que las posibilidades de conexión dependían en la mayoría de los casos de su propio equipo, que no todo el mundo tenía, o no vivía en zonas conectadas con fibra óptica o con banda ancha de muy alta velocidad.

La retórica marcial de la «guerra» contra el virus tiene otra función, evitar el debate y amordazar toda oposición en nombre de la unión sagrada. En el plano social, la pandemia ha sido una oportunidad para imponer, oficialmente de forma provisional, la suspensión de los derechos laborales (vacaciones pagadas, horarios de trabajo semanales, etc.) y reformas muy discutidas por manifestaciones ahora prohibidas. Entre ellas, la «ley de programación de la investigación plurianual», que suscitó a principios de 2020 la oposición casi unánime de todas las organizaciones corporativas y sindicales — habitualmente divididas—, y la reforma de la escuela secundaria (Martinache, 2020). Y a pesar del confinamiento, que priva a los estudiantes de secundaria del asesoramiento y las posibilidades de conexión en su centro escolar, Blanquer no aplazó las fechas de solicitudes de plaza para la universidad a través de Parcoursup, el programa informático para formular las elecciones de orientación que sirve, de hecho, para seleccionar y como máquina de disuadir a los jóvenes de que continúen en la enseñanza superior (Poullaouec y Hugrée, 2018; Clément, Couto, Blanchard, 2019). Y el ministro, que ya mostraba un ostentoso desinterés por la formación profesional, lo confirmó durante el encierro, al no responder a ninguna pregunta sobre la posibilidad de llevar a cabo una formación profesional a distancia, a sabiendas de que requiere maquinaria, ropa, manipulación directa, etc. (Depoilly y Maillard, 2020).

Investigaciones realizadas durante el confinamiento han evidenciado el intento de instrumentalización de la situación para controlar aún más la labor de los profesores, apropiándose de las interfaces informáticas (Cartable en ligne, Pronote, etc.) como instrumentos de control (Frajerman, 2020) ${ }^{11}$. En Francia, los directores de las escuelas primarias no son los superiores jerárquicos de los profesores, que sólo responden ante el inspector. Asimismo, los directores de los centros de secundaria y de bachillerato no han tenido históricamente ningún derecho de control sobre el contenido de la enseñanza, que también ha sido controlado por los inspectores, para garantizar la igualdad de la enseñanza en el territorio y evitar a los poderes locales. Es esta independencia de los docentes lo que tratan de socavar desde hace años las políticas neoliberales y la nueva gestión pública, en nombre de los «proyectos» y las dinámicas locales. Pero ante la ineficacia de las herramientas informáticas de la Educación Nacional (en gran parte debida a

11 Cartable en ligne (mochila en línea) es una intranet académica para profesores, alumnos, padres y equipo directivo que cuenta con dosieres personales de los alumnos, servicio de mensajería y aplicaciones pedagógicas. Pronote es un programa informático usado en las escuelas francesas para la gestión de lo que denominan la «vida escolarn: pasar lista, convocar a alumnos, enviar SMS, controlar las ausencias y retrasos, programar castigos, consultar los dosieres de los alumnos o el menú escolar. (Nota del revisor). 
la falta de financiación), los profesores han utilizado otros programas informáticos y redes sociales para mantenerse en contacto con los padres (Montmasson-Michel, 2020; Pirone y Delès, 2020; Thin, 2020), y así han escapado a este control militar, con la aprobación tácita de las jerarquías intermedias que han priorizado la eficacia (Frajerman, 2020). Pero el ministro Blanquer y la mayoría presidencial, en lugar de reconocer la dedicación de la gran mayoría de los profesores, están tratando de instrumentalizar la crisis. Porque, hacia el final del confinamiento, varios indicios sugieren que la cima de la pirámide quería corregir esta falta de control. Así, el 12 de mayo, una diputada de la mayoría presidencial registró un proyecto de ley para redefinir la función de los directores de escuelas primarias a fin de incrementar «su poder de decisión», y un decreto del 12 de junio abrió unas nuevas oposiciones para el cuerpo de directores de centros de secundaria a directivos provenientes del sector privado.

No todo es cuestión de cálculo. Es cierto que la urgencia del confinamiento se ha impuesto al gobierno, así como la evaluación de los riesgos se ha ido midiendo por la evolución del número de casos y muertes, lo que ha llevado a muchas decisiones abruptas y contradictorias, como que las escuelas se cerraran porque los niños son transmisores, para luego decir lo contrario un mes después, con el progreso del conocimiento sobre el virus.

Pero no es en absoluto creíble que el Ministerio no contemplara, ya el 12 de marzo, el escenario de una interrupción de seis meses de la escolaridad hasta el verano, lo que casi ha sido así, ni el escenario que finalmente se ha vivido, de una breve reanudación sólo para la escuela primaria y secundaria inferior, las dos últimas semanas antes del verano, ambas simbólicas, para volver a poner en marcha a los alumnos y permitir a los padres reanudar el trabajo. Sin embargo, si este escenario se hubiera presentado y debatido, habría llevado inexorablemente a considerar medidas de gran alcance, las únicas capaces de hacer que todos los niños del país volvieran a la escuela y de respetar las distancias de seguridad: dividir las clases en dos o tres subgrupos para respetar el número máximo de 10 personas reunidas. Esto habría significado hacerse con locales (y pagar alquileres) — ya que apenas hay aulas vacías en las escuelas- y la contratación masiva y urgente de profesores y su formación. Solo estas medidas habrían permitido hacer frente realmente a la situación, que es la del comienzo del año escolar en septiembre de 2020, y que obviamente durará todo el año, antes de que las vacunas o los tratamientos reduzcan la amenaza de la COVID. Esta política, en sentido opuesto a la austeridad, no fue presentada, por lo tanto, por el gobierno como una opción, que centró la atención en escenarios provisionales: primero el plan ilusorio de una reanudación rápida tras el cierre de las escuelas, luego el de una vuelta a las aulas para los hijos de los trabajadores «prioritarios» (sanidad, transporte, etc.) el 11 de mayo, y después para todos el 22 de junio. Los complacientes medios de comunicación se apresuraron a informar sobre los debates impuestos por la cuestión de las modalidades de reanudación en estos plazos. Así, habrán pasado seis meses sin que se pudieran debatir democráticamente las condiciones de la vuelta a la escuela. Vemos aquí la traducción de las concepciones de la Nueva Gestión Pública, según la cual los cambios deben ser implementados sin ser presentados como opciones. Hasta la fecha, 5 de septiembre de 2020, al final de la primera semana del nuevo año escolar, hay escuelas enteras que están cerradas debido a los casos de COVID, pero no se hace ningún recuento oficial.

\section{6. ¿̇Hacia una escuela a la carta y el fin de la escolaridad única?}

Como hemos dicho, con la creciente crisis económica, las opciones contradictorias se van agudizando. Para apoyar al sector financiero, el gobierno debe liberar dinero y reducir el gasto en servicios públicos 
amplificando las políticas de austeridad: si las «soluciones» que adopta perjudican a los servicios públicos, aunque hayan demostrado su utilidad, no es solo por la ideología, aunque esta intervenga. Estas políticas amplían las lógicas ya iniciadas de apoyo abierto a la enseñanza privada y de reconfiguración de la pública hacia un núcleo de "fundamentos», más allá de los cuales los objetivos más ambiciosos se remiten a la política de opciones (abiertas al sector privado a través de la enseñanza a distancia, clases pagadas, asociaciones, etc.) basada en el modelo anglosajón.

Ganando seis meses, de marzo a septiembre, para evitar crear las condiciones de una verdadera reanudación de la escolarización de los niños de todas las clases sociales, e incluso manifestando a finales de junio y principios de septiembre que la reanudación parcial está teniendo lugar sin las condiciones de seguridad (el caso de 30 estudiantes de secundaria hacinados en una clase estrecha y calurosa por el clima de verano no es nada raro), el gobierno impone que ocurra lo mismo al principio del año escolar y probablemente durante buena parte del curso 2020/2021.

Además, la reanudación parcial a finales de junio se hizo solo a media jornada para evitar las aglomeraciones en los patios de recreo y reducir el número de alumnos por clase: había que buscar la educación suplementaria fuera de la escuela. Esto podría ser anecdótico. Pero coincide con lógicas más profundas que se actualizan en los nuevos proyectos de reforma presentados con motivo del desconfinamiento.

De hecho, lógicas similares contribuyen al proyecto de reforma de las llamadas 2S2C ${ }^{12}$ (Deporte-Salud-Cultura-Civismo) en el momento de la reanudación parcial de la escolaridad a principios de junio.

La imposición de la reanudación solo a tiempo parcial en junio planteó la cuestión de qué hacen los niños el resto del tiempo y de qué contenidos deben eliminarse para poder ocuparse del resto en el tiempo asignado. Si, en el contexto de una reanudación previa puntual y excepcional antes del verano, la medida podría haber parecido técnica, muy rápidamente las declaraciones del ministro revelaron una clara instrumentalización de la crisis, cuando reconoció que se trataba de cambios que ya había previsto hacer, y cuando invocó las tardes sin clases del modelo alemán planteándose apelar al voluntariado en las áreas de los deportes y de la creatividad, utilizando recursos locales.

De hecho, proyectos antiguos planteaban subcontratar la Educación Física y Deportiva (EPS ${ }^{13}$, a cargo de profesores de escuelas polivalentes en el primer grado y de profesores específicos en el segundo grado), así como las de artes (educación musical y artes plásticas con profesores especializados en secundaria y de nuevo a cargo de maestros de primaria).

Jean-Michel Blanquer, primero como solución técnica de «custodia» de los niños en el desconfinamiento parcial antes del 22 de junio, y luego de manera sistemática, propone reducir aún más el tiempo de escolarización. El primer objetivo es económico: en nombre del «modelo alemán» (que no aspira a la igualdad...), se trata de dar un paso más allá en las políticas de austeridad, reduciendo el número de profesores, que sólo tendrían grupos con la mitad de la clase en alternancia y confiando la otra mitad del tiempo al sector privado (aunque sea asociativo). Por supuesto, los artistas y deportistas encontrarían ingresos extra en ello, pero en términos económicos generales, si son sustituidos por profesores, esto no reduce en absoluto el número de desempleados, e incluso aumenta el empleo precario en detrimento de

\footnotetext{
12 2S2C es el acrónimo de las iniciales en francés de Sport (Deporte) y Santé (Salud) para las dos eses y Culture (Cultura) y Civisme (Civismo) para las dos ces (Nota del traductor).

13 EPS es el acrónimo de Éducation Physique et Sportive (Educación Física y Deportiva) (Nota del traductor).
} 
los puestos de trabajo estables. Sobre todo, la satisfacción de las necesidades culturales y deportivas amplía el mercado del «ocio»: cuando las autoridades locales no quieran o no puedan tomar el relevo de los funcionarios locales, la «elección» de las actividades dependerá de las propuestas del sector voluntario y del sector comercial, en ambos casos facturadas a las administraciones o a las familias.

Otra dimensión es la curricular, sobre los objetivos asignados al tiempo de enseñanza. En primer lugar, se trata de hacer desiguales los objetivos de las escuelas, en función, por supuesto, de su composición social: el «descubrimiento» de diferentes prácticas artísticas, o de distintos deportes, está condicionado tanto por los medios financieros para remunerar a los profesionales, como por los recursos locales: los territorios son desigualmente ricos en diferentes actividades físicas y deportivas, en prácticas culturales y científicas distintas, y en potenciales participantes. Al limitar las opciones curriculares, el gobierno impone el fin del objetivo de construir una cultura común entre los futuros ciudadanos franceses. Porque sólo el Estado puede garantizar que se busquen los mismos objetivos de transmisión para todos los niños del país... Es tener la memoria un poco corta, sólo cinco años después de los atentados, cuando se constataba que los jóvenes que habían crecido en la República necesitaban compartir mejor la cultura común.

Además, en el contenido mismo, esta transferencia de las artes y los deportes refleja la intención de no enseñarlas más, es decir, de no transmitir ya los saberes, la comprensión y las prácticas, para cambiar la forma en que los estudiantes ven estas prácticas sociales. La enseñanza del deporte y de las artes no tiene como objetivo principal el rendimiento deportivo o creativo, sino el desarrollo en cada individuo de una serie de intereses que no pueden transmitirse en todas las familias. Tiene también el objetivo de transmitir herramientas para la comprensión de los diferentes aspectos de la cultura humana acumulada a lo largo de la historia y que continúan renovándose. La transferencia a otros profesionales implica un cambio de perspectiva, de la enseñanza a todos, hacia el consumo del ocio y las pasiones previamente creadas, en nombre de una respuesta individualizada a las «necesidades».

Jean-Michel Blanquer fue muy claro. Para él, las artes y el deporte se refieren a la «realización», mientras que los «fundamentos» se refieren al aprendizaje. Las palabras están desprovistas de ambigüedad: el desarrollo es como una planta, una evolución programada desde el interior, bastaría con tener condiciones ambientales que dejen hacer a esta fuerza centrífuga, prácticamente considerada como «natural», como en la ideología de los dones, o al menos considerando que debemos contentarnos con ver si «ya está ahí». Para el ministro, no se trata de permitir que todos los jóvenes cambien aprendiendo cosas nuevas en estos ámbitos, sino de invitar a cada uno a disfrutar de lo que ya ha aprendido a apreciar como resultado de su socialización familiar, y de acuerdo con sus medios económicos. Por lo tanto, se trata de «opciones» muy limitadas, económica y socialmente, como ya sabemos por las prácticas tuteladas de los niños en los clubes o conservatorios durante el tiempo de ocio.

En el discurso de Jean-Michel Blanquer, este «desarrollo» apunta explícitamente a una especie de condicionamiento del bienestar para que los llamados aprendizajes «fundamentales» se hagan con el «placer de aprender». Pero ¿por qué no se prevé que el placer pueda surgir del aprendizaje de nuevas prácticas culturales y físicas?

Esta reforma convierte a los animadores de las ciudades o de las asociaciones en subdocentes, mientras que su contribución se puede situar en un campo completamente diferente, no en el de la enseñanza, sino en el de lo que se puede adquirir a través del juego. ¿Y suponemos que basta con ser novelista o 
estadístico para enseñar literatura o matemáticas? ¿Qué convertiría automáticamente a un deportista, o a un entrenador de club que busca el rendimiento en una sola práctica, en un profesor que enseña una pluralidad de deportes? ¿Y qué nos lleva también a pensar que un músico o un artista plástico es capaz de formar espontáneamente a los jóvenes para que entiendan y aprecien su arte? Enseñar no consiste solo en repartir fichas y links a distancia, ni tampoco en mostrar que se es una persona apasionada por una práctica, sino que es un oficio que se aprende.

La enseñanza es precisamente la transmisión a través del estudio, a través del ejercicio, que también están presentes en EPS (hacer un alto en una situación para poder identificar qué compañeros estaban desmarcados o los fallos en la defensa que podrían haber sido explotados si el atacante no hubiese arremetido sin miramientos...) como en la enseñanza de las artes (comparación de la construcción de piezas musicales o la distribución de los colores). Las alianzas con colaboradores externos, culturales, deportivos, científicos o de otro tipo, son precisamente pertinentes cuando los docentes se reapropian de estos encuentros y los convierten en objetos para ser estudiados y comprendidos (Bonnéry y Deslyper, 2020), y no sólo para probar o practicar en el registro evidente del entusiasta iniciado por su familia desde muy joven.

Entre la reducción de lo que se enseña, al remitir el resto a opciones en línea y/o de pago, al ámbito del ocio de pago, el gobierno está empujando a cada familia a encontrar otras soluciones de forma individual: ya sea estudiando a distancia a largo plazo y totalmente para las familias que tienen los medios financieros y pedagógicos para acompañar esta modalidad, o buscando el complemento del mínimo realizado en el aula acudiendo al sector privado, o bien conformándose con este mínimo.

Claramente, hay una lógica que lleva, sin decirlo, al final de la escuela única. Esta dista mucho de ser perfecta, resultado de un compromiso inestable entre el progreso de la democratización (plan de estudios y objetivos unificados para la escuela primaria y el primer ciclo de secundaria, acceso masivo a la secundaria superior y a la educación superior) y mecanismos de selección fuertemente marcados según los orígenes sociales (éxito en el aprendizaje, orientación, modalidades estancas). Pero sigue teniendo el mérito de fijar el mismo objetivo para todas las clases sociales y, al hacerlo, de constituir un punto de referencia y de reivindicación para cuestionar todo lo que contribuya a diferenciar los objetivos y el tratamiento según los orígenes sociales. Este cuestionamiento se confirma con la reforma que Jean-Michel Blanquer llevó a cabo con motivo del desconfinamiento.

\section{Conclusión}

Las desigualdades escolares parecen haber aumentado durante la primera fase del confinamiento, pero han comenzado a surgir las primeras aproximaciones entre padres y maestros, tratando de entenderse. Los profesores han descubierto a ciertas familias, implicadas aunque discretas y poco acomodadas, mientras que el discurso dominante las consideraba negligentes, y los padres han visto a los maestros preocupados por la situación de sus hijos.

Pero el gobierno reorientó rápidamente la situación hacia la competición, con la incorporación de tan solo una parte de los alumnos en junio, con la reducción de la escuela pública a solo una parte de las disciplinas y de los contenidos, y con el traspaso a cada familia de la responsabilidad de encontrar soluciones para instruir a los niños y adolescentes en lo que ya no se enseñará. 
Encontramos las mismas lógicas que se habían desplegado anteriormente, con otros gobiernos, pero los mismos «altos funcionarios» consejeros, durante los ataques al mapa escolar ${ }^{14}$, y la incitación a hacer «proyectos educativos de centro» que compiten entre sí, y ponen en competencia entre sí a los estudiantes que se benefician de opciones cada vez más desiguales.

En el fondo del asunto está la cuestión del futuro de la escuela pública. Lo que esbozan las reformas actuales, que el gobierno intenta imponer en el contexto de la crisis sanitaria, es su reducción al mínimo. Por el contrario, el desarrollo de los conocimientos y las formas de pensar en la sociedad exige que estos se compartan más ampliamente. Esta sería una forma de resolver la crisis de la escuela, renunciando a la democratización y aplicando una política decididamente desigualitaria: el sistema ya no tropezaría con objetivos no alcanzados, ya que no serían los mismos entre los alumnos, con un plan de estudios obligatorio reducido.

Otra forma de resolver la contradicción, por el contrario, es redefinir lo que se debe enseñar a toda una generación, dar un nuevo impulso a la contratación y a la formación de los profesores teniendo más en cuenta los resultados de la investigación en educación que permiten considerar formas de enseñanza menos diferenciadoras.

\section{Referencias bibliográficas}

Bautier, Élisabeth y Rochex, Jean-Yves (1997-2007): “Apprendre: des malentendus qui font la différence?” en: Jérôme Deauvieau y Jean-Pierre Terrail (eds.): Les sociologues, l'école et la transmission des savoirs. París: La Dispute.

Bautier, Élisabeth (2011). Pour une égalité scolaire: la question de la langue et des savoirs. L'Éducation nationale en danger. París: Note de la fondation Copernic.

Bautier, Élisabeth; Bonnéry, Stéphane y Clément, Pierre (2017): “L'introduction en France des compétences dans la scolarité unique: enjeux politiques, enjeux de savoir, enjeux pédagogiques et didactiques”. Cabiers de la Recherche sur l'Éducation et les Savoirs, 16, 73-93.

Ben Ayed, Choukri (dir.) (2010). L'école démocratique. Vers un renoncement politique? París: Armand Colin.

Bonnéry, Stéphane (2007). Comprendre l'échec scolaire. París: La Dispute.

Bonnéry, Stéphane y Deslyper, Rémi (2020): “Enseignement de l'art, Art à l'école: tour d’horizon des recherches en France". Cabiers de la Recherche sur l'Éducation et les Savoirs, número extraordinario, 7 (1) 5-40. https://journals.openedition.org/cres/4220.

Bonnéry, Stéphane y Douat, Étienne (dir.) (2020). L’éducation aux temps du coronavirus. París: La Dispute.

Bourdieu, Pierre y Passeron, Jean-Claude (1970). La reproduction. París: Les Éditions de Minuit.

Canard, Bruno (2020): "Les découvertes réalisées sur le coronavirus". Fondation de la Recherche Médicale. https://www.frm.org/coronavirus-virus-emergents/itw-coronavirus-bruno-canard.

14 La carte scolaire es el sistema que regula el proceso de admisión y asignación del alumnado a los centros escolares en Francia en función de las zonas geográficas en las que se ubica su domicilio. Se creó en los años 60 con el objetivo de organizar la oferta escolar y lograr una mejor distribución de los alumnos entre los centros escolares, aunque en un inicio sin el objetivo de lograr una mayor mezcla social. Ha sido reformada varias veces y se ha debatido su efecto en la reducción o el refuerzo de la segregación. (Nota del revisor). 
Clément, Pierre; Couto, Marie-Paul y Blanchard, Marianne (2019): "Parcoursup : infox et premières conséquences de la réforme”. La Pensée, 399, 144-156.

Clot, Yves (1988). Le symptôme scolaire. París: Sepirm.

Depoilly, Séverine y Maillard, Fabienne (2020): “Enseignement professionnel et continuité pédagogique: omissions politiques et impasses pédagogiques” en Stéphane Bonnéry y Étienne Douat (dir.): L'éducation aux temps du coronavirus. París: La Dispute.

Frajerman, Laurent (2020): “La continuité pédagogique et les méthodes managériales” en Stéphane Bonnéry y Étienne Douat (dir.): L'éducation aux temps du coronavirus. París: La Dispute.

Henri-Panabière, Gaële, Mercklé, Pierre y Gouasdé, Rémi (2020): “Interroger des étudiant.s confinés: un questionnaire impossible?” en Stéphane Bonnéry y Étienne Douat (dir.): L'éducation aux temps du coronavirus. París: La Dispute.

Martinache, Igor (2020): “Le confinement, un précipité de la réforme du lycée?” en Stéphane Bonnéry y Étienne Douat (dir.): L'éducation aux temps du coronavirus. París: La Dispute.

Millet, Mathias y Vaquero Stéphane (2020): “Les heurts du distanciel. Chronique d'une rupture pédagogique à l'université" en Stéphane Bonnéry y Étienne Douat (dir.): L'éducation aux temps du coronavirus. París: La Dispute.

Montmasson-Michel, Fabienne (2020): "Une étrange parenthèse pédagogique à l'école” en Stéphane Bonnéry y Étienne Douat (dir.): L'éducation aux temps du coronavirus. París: La Dispute.

Pasquier, Dominique (2018). L'Internet des familles modestes, enquête dans la France rurale. París: Presses des Mines.

Pirone, Filippo y Delès, Romain (2020): “Des contacts forts... des inégalités intactes”. Cabiers pédagogiques, $563,5-12$.

Poullaouec, Tristan y Hugrée, Cédric (2018): “Mobilisations contre la sélection à l'université: quelle stratégie?". Contretemps, avril, 1-8.

Poullaouec, Tristan y Lemêtre, Claire (2009): "Retours sur la seconde explosion scolaire". Revue française de pédagogie, 167, 5-11.

Rayou, Patrick (2000): “L'enfant au centre. Un lieu commun 'pédagogiquement correct”" en Jean-Louis Derouet (dir.): L'école dans plusieurs mondes. INRP. París: De Boeck \& Larcier.

Rochex, Jean-Yves (1991): “L'implosion scolaire” en Jean-Pierre Durand y François-Xavier Merrien (dir.): Sortie de siècle. La France en mutation. París: Vigot.

Sève, Lucien (1964): “Les dons n'existent pas”. L'École et la Nation, octobre.

Terrail, Jean-Pierre (1984): "Familles ouvrières, école, destin social (1880-1980)". Revue française de sociologie, XXV, 421-436.

Thin, Daniel (2020): “La scolarisation de l'espace familial au quotidien” en Stéphane Bonnéry y Étienne Douat (dir.): L'éducation aux temps du coronavirus. París: La Dispute. 


\section{Nota biográfica}

Stéphane Bonnéry es catedrático del departamento de Ciencias de la Educación de la Universidad París 8 y miembro del grupo de investigación CIRCEFT-ESCOL. Sus trabajos buscan comprender la renovación de las desigualdades escolares y culturales entre los niños y jóvenes, articulando la sociología de la educación con aportaciones de la didáctica, la historia y los estudios literarios. Su investigación se centra en la comprensión de la actividad de los estudiantes frente a los currículos, las formas pedagógicas o los dispositivos de atención a alumnos con dificultades, y en el análisis de la evolución de la forma escolar, los saberes y su organización, y su relación con otras formas de socialización. Es autor de Comprendre l'échec scolaire (La Dispute, 2007) y recientemente ha coordinado los libros Supports pédagogiques et inégalités scolaires (La Dispute, 2015) y L'éducation aux temps du coronavirus (La Dispute, 2020, junto con Etienne Douat). 